\title{
Enantioselective bioaccumulation and toxic effects of fipronil in the earthworm Eisenia foetida following soil exposure
}

\author{
Fang Qin, ${ }^{\mathrm{a}, \mathrm{b}}$ Yongxin Gao, ${ }^{\mathrm{a}}$ Peng $\mathrm{Xu},{ }^{\mathrm{a}}$ Baoyuan Guo, ${ }^{\mathrm{a}}$ Jianzhong $\mathrm{Li}^{\mathrm{a}}$ \\ and Huili Wang ${ }^{\mathrm{a}^{*}}$
}

\begin{abstract}
BACKGROUND: Enantiomers of chiral pesticides often have different bioactivity, toxicity and environmental behaviours. Fipronil has been used in racemate for agricultural purposes against soil insects, leading to increased inputs into soil environments and complex biota exposures. To understand the potential risk associated with fipronil enantiomer exposure, subchronic toxicity and bioaccumulation tests with earthworms (Eisenia foetida) in fipronil-spiked soils were evaluated under laboratory conditions.
\end{abstract}

RESULTS: Enantioselective toxicity was measured in E. foetida biomass after 28 days of subchronic exposure, with increased toxicity from racemate and $S$-fipronil compared with $\boldsymbol{R}$-fipronil. The bioaccumulation of fipronil in earthworm tissues was also enantioselective, with a preferential accumulation of $S$-fipronil, and the enantiomer fraction was approximately $0.56-0.60$. During soil exposure, fipronil was transformed primarily into fipronil sulfide, sulfone and amide, and $E$. foetida rapidly accumulated fipronil and sulfone.

CONCLUSION: This work demonstrates the enantioselective subchronic toxicity and bioaccumulation of enantiomers of fipronil in $E$. foetida. The earthworm tissues exhibited a relative enrichment of fipronil and fipronil sulfone, and these compounds might biomagnify (with a biota-to-soil accumulation factor of $\geq 1.0 \mathbf{k g}_{\text {oc }} \mathbf{k g}_{\text {lip }}^{-1}$ ), allowing for the possible trophic transfer and/or bioaccumulation of all these chemicals if earthworms were consumed by predator organisms.

(C) 2014 Society of Chemical Industry

Supporting information may be found in the online version of this article.

Keywords: chiral pesticides; enantioselective; toxicity; bioaccumulation; soil; fipronil

\section{INTRODUCTION}

Fipronil - $(R, S)$-5-amino-1-(2,6-dichloro- $\alpha, \alpha, \alpha$-trifluoro- $p$-tolyl)-4trifluoromethyl-sulfinylpyrazole-3-carbonitrile (CAS number 120068-37-3) - is an important phenyl pyrazole insecticide used for insect control and plant protection. It is effective against a wide range of insect pests and has been used on a large number of crops. ${ }^{1,2}$ Fipronil contains one chiral centre and two mirror image forms or enantiomers called $R$ - and $S$-fipronil. ${ }^{3}$ Fipronil was introduced into the market as a racemic formulation. Enantiomers of fipronil differ in their biological activity, toxicity, effects on beneficial and non-target organisms and environmental fate. ${ }^{4-8}$ These differences may lead to variations in microbial degradation rates and would indicate that one enantiomer is more persistent in the environment than the others. Many reports have documented enantioselective degradation or transformation in sediment, ${ }^{9}$ plants ${ }^{4,10}$ and animals ${ }^{11}$ when rac-fipronil was applied.

In China, fipronil is primarily used as a seed-coating formulation for agricultural purposes against soil insects, such as wireworms. Raveton et al. ${ }^{12}$ reported that only $7 \%$ of the fipronil had been absorbed by the sunflower plant from a seed-coating formulation, and most fipronil was found in the soil. Therefore, this application resulted in widespread soil contamination. Under field conditions, fipronil has a half-life of 5.6-135 days in soils, and its average half-life in soils is approximately 65 days. ${ }^{13,14}$ Pesticide degradation is important because it permits a prediction of the potential risk associated with exposure. ${ }^{15}$ Fipronil reportedly underwent photolysis to fipronil desulfinyl, ${ }^{16}$ oxidation to fipronil sulfone, ${ }^{17}$ reduction to fipronil sulfide ${ }^{18}$ and hydrolysis to fipronil amide $^{19,20}$ (Fig. 1). The rate and route of pesticide metabolism varied according to environmental factors. ${ }^{4}$

The earthworm (Eisenia foetida) is widely distributed and frequently dominant in soil communities. These worms have intimate contact with soils and have been designated as representative organisms for use in soil system bioassays. These organisms have played a major role in ecological assessments, particularly with reference to the bioaccumulation/bioavailability of chemicals and

\footnotetext{
* Correspondence to: Huili Wang, Research Centre for Eco-Environmental Sciences, Chinese Academy of Sciences, 18 Shuangqing Road, Haidian District, Beijing 100085, China.E-mail: huiliwang@rcees.ac.cn

a Research Centre for Eco-Environmental Sciences, Chinese Academy of Sciences, Beijing, China

b Department of Environmental Engineering, North China Institute of Science and Technology, Yanjiao, Beijing, China
} 


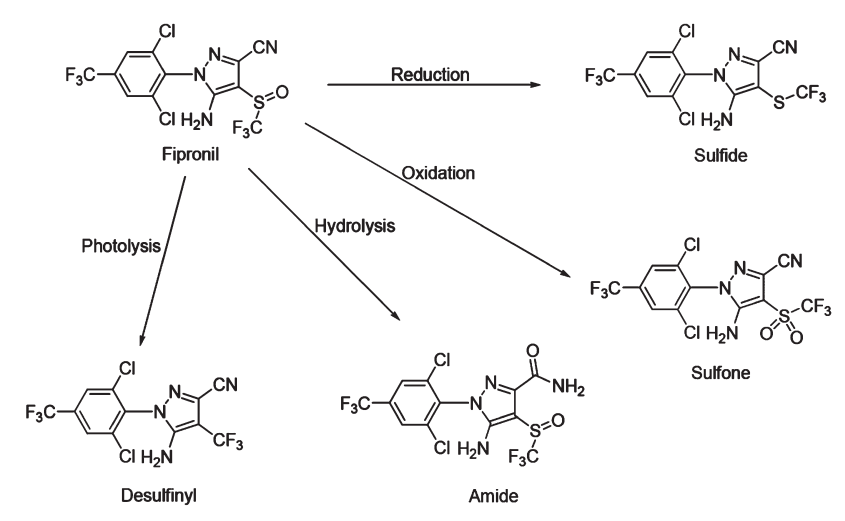

Figure 1. Metabolites or degradation products of fipronil.

heavy metals. ${ }^{21-23}$ Several papers have reported that $E$. foetida were used in both toxicity and bioaccumulation studies, ${ }^{24-26}$ but data about the enantioselective bioaccumulation of enantiomers of fipronil in earthworms have not been reported. Although fipronil had no acute toxicity in earthworms, ${ }^{27}$ this compound did reduce the rate of reproduction $\left(\mathrm{EC}_{20}=23.16 \mathrm{mg} \mathrm{kg}^{-1}\right) .{ }^{28}$ Fipronil and its soil metabolites may be accumulated by earthworms and then transferred and/or bioaccumulated into predator organisms that consume earthworms. ${ }^{29}$

In the present study, the commonly used test species $E$. foetida was selected for subchronic toxicity and bioavailability tests under laboratory conditions. The objectives of this study were (i) to evaluate the subchronic toxicity of fipronil and its enantiomers to $E$. foetida by using fipronil-spiked soils, (ii) to investigate the enantioselective bioaccumulation of fipronil in E. foetida from soils and (iii) to quantify major fipronil metabolites in soils and E. foetida over the course of exposure.

\section{MATERIALS AND METHODS}

\subsection{Chemicals and reagents}

Analytical standards for fipronil racemate (purity 99.0\%, enantiomeric ratio $[R] /[S]=0.99$ ) were obtained from the National Pesticide Quality Supervision and Inspection Centre (Beijing, China). Fipronil sulfide (MB45950, 99.5\%) and fipronil sulfone (MB46136, 99.0\%) were obtained from Dr. Ehrenstorfer Gmbh (Augsburg, Germany). Fipronil desulfinyl (MB46513, $100 \mu \mathrm{g} \mathrm{mL}^{-1}$ ) and fipronil amide (RPA200766, $100 \mu \mathrm{g} \mathrm{mL}^{-1}$ ) were obtained from the AccuStandard (New Haven, CT). R-Fipronil and S-fipronil were obtained by high-performance liquid chromatography on a Chiralcel OD-RH semi-preparation column $(20 \times 250 \mathrm{~mm}$ i.d., particle size $5 \mu \mathrm{m}$; Daicel, Shanghai, China) at $25^{\circ} \mathrm{C}$ with a mobile phase of $50 / 50$ acetonitrile/water at $5.0 \mathrm{~mL} \mathrm{~min}^{-1}$, and the UV detection wavelength was $280 \mathrm{~nm}$. Both enantiomeric purities were $97.0 \%$ (supporting information Fig. S2 and S3). As in the published procedures, ${ }^{30-32}$ the $S$-fipronil in the acetonitrile/water mobile phase elutes first on a column cellulose tri-3,5-dimethylphenyl carbamate chiral stationary phase. The first eluted enantiomer was $S$-fipronil, and the second eluted enantiomer was $R$-fipronil. The water was purified with a Milli-Q system. Acetonitrile (HPLC grade) was obtained from Fisher Scientific (Fair Lawn, NJ). Silica-based sorbents including $\mathrm{C}_{18}(40 \mu \mathrm{m}$ particle size) and primary secondary amine (PSA) $\left(\mathrm{Si}-\left(\mathrm{CH}_{2}\right)_{3}-\mathrm{NH}-\left(\mathrm{CH}_{2}\right)_{2}-\mathrm{NH}_{2}\right)(40 \mu \mathrm{m}$ particle size) were obtained from Agela Technologies (Tianjin, China). All other chemicals and solvents were of analytical grade and commercially available.

\subsection{Eisenia foetida}

Mature earthworms ( $E$. foetida) were purchased from the northern suburban farm of Changping (Beijing, China), and they were maintained in a wooden breeding box $\left(50 \times 50 \times 20 \mathrm{~cm}^{3}\right)$ containing a mixture of soil and cattle manure. Active, sexually mature (with well-developed clitella) worms with body masses between 200 and $300 \mathrm{mg}$ were used in the experiment.

\subsection{Soil collection}

The soil collection site was a farm in the Changping District of Beijing, China, which had not received any pesticide applications for at least 10 years. The topsoil $(0-10 \mathrm{~cm})$ was collected after removing vegetation. The soils were sieved $(2 \mathrm{~mm})$, air dried at room temperature and stored in a dark, dry place until a few days before they were used. The physicochemical properties of the soil were as follows: clay loam texture, organic matter $3.22 \pm 0.12 \%$, clay $4.2 \pm 0.1 \%$, silt $38.0 \pm 1.1 \%$, sand $55.1 \pm 1.2 \%$ and $\mathrm{pH}$ (soil:water ratio $1: 2.5) 7.12 \pm 0.20$.

\subsection{Toxicity test}

Toxicity tests were conducted by exposing the $E$. foetida to fipronil racemate, $R$-fipronil or $S$-fipronil for 28 days in the test soils. Based on a range-finding exposure test, a series of standard working solutions of fipronil racemate and each enantiomer were prepared in acetone. A vehicle control (acetone) was tested to evaluate the potential effects of acetone toxicity. Fipronil racemate and the individual enantiomers were each dissolved in $10 \mathrm{~mL}$ of acetone, and then the acetone solution was slowly added to dry soil $(50 \mathrm{~g})$ while mixing continued for approximately $5 \mathrm{~min}$. The spiked soil was left in a fume cupboard overnight; after that time, the acetone had evaporated. The contaminated dry soil $(50 \mathrm{~g})$ was then mixed thoroughly with $200 \mathrm{~g}$ of uncontaminated medium, and then the contaminated soil $(250 \mathrm{~g})$ was transferred to circular glass containers with a diameter of $12.5 \mathrm{~cm}$ and a height of $9.5 \mathrm{~cm}$. The final concentrations of fipronil racemate and each enantiomer in soil were 50, 100, 200, 400, 800 and $1000 \mathrm{mg} \mathrm{kg}^{-1}$. Distilled water $(90 \mathrm{~g})$ was added to each jar to restore the content of water to $36 \%$.

The $E$. foetida were acclimated to the test soils for 1 week prior to the start of the test. Use was made of three replicates (beakers) per concentration and ten vehicle control replicates. Before the start of the test, the worms were placed on moist filter paper to evacuate most of their gut contents for $3 \mathrm{~h}$ at $20^{\circ} \mathrm{C}_{i}^{21}$ the depurated worms were weighed individually, and ten individuals were then placed in each test container. This process, which eliminated the gut contents, had no effect on the growth or survival of $E$. foetida when comparing evacuated worms from untreated soils. Test vessels were randomly arranged in a cultivation cabinet and maintained at $20 \pm 2{ }^{\circ} \mathrm{C}$ with a photoperiod of $16 \mathrm{~h}$ light and $8 \mathrm{~h}$ dark (fluorescent, 400-800 lux). The loss of water by evaporation from inside the jars was compensated for by adding distilled water every 2 days according to the weight changes of the control jar. All worms were removed from their containers on the last day of the bioassay. The individuals that did not respond to mechanical stimulation of the anterior portion of their bodies were recorded as dead. No worm was found to be dead or missing in the treatment and control groups during the toxicity test. Live worms were washed, allowed to evacuate their gut contents, blotted dry and weighed $(0.01 \mathrm{mg})$. Average weights were measured before and after the 28 day test. Soil samples were collected from test beakers (1, 2, $3,7,14,21$ and 28 days) and analysed separately to confirm the 
concentrations of fipronil during the toxicity test. The growth (dry weight) of surviving $E$. foetida was regressed against exposure concentrations in Origin 8.0 (OriginLab Corp, Northampton, MA) to evaluate toxicity trends.

\subsection{Eisenia foetida bioaccumulation and elimination}

To ensure that $250 \mathrm{~g}$ of medium was spiked homogeneously with rac-fipronil, $R$-fipronil and $S$-fipronil, the procedure steps (dilution spike) were as follows. Firstly, 5.0 and $12.5 \mathrm{mg}$ of rac-fipronil and $2.5 \mathrm{mg}$ of $R$-fipronil and $S$-fipronil were dissolved in $10 \mathrm{~mL}$ of acetone, and the same process that was used for the toxicity test was used to prepare the spiked soils for the bioaccumulation test. The acetone solution was slowly added to dry soil $(50 \mathrm{~g})$. After the acetone had evaporated, the contaminated dry soil $(50 \mathrm{~g}$ ) was mixed thoroughly with $200 \mathrm{~g}$ of uncontaminated medium, and then the contaminated soil $(250 \mathrm{~g})$ was transferred to a $500 \mathrm{~mL}$ glass jar. The final concentrations of rac-fipronil in soil were 20 and $50 \mathrm{mg} \mathrm{kg}^{-1}$. The concentrations of $R$-fipronil and S-fipronil in soil were $10 \mathrm{mg} \mathrm{kg}^{-1}$ each. Distilled water $(90 \mathrm{~g})$ was added to each jar to restore the content of water to $36 \%$.

The E. foetida used in the bioaccumulation test weighed between 200 and $300 \mathrm{mg}$ and were acclimated to the test soils for 1 week prior to the start of the test. Use was made of three replicates per concentration and ten vehicle control replicates. The test vessels were randomly arranged in an incubator and maintained at $20 \pm 2{ }^{\circ} \mathrm{C}$ with a photoperiod of $16 \mathrm{~h}$ light and $8 \mathrm{~h}$ dark (fluorescent, 400-800 lux). The E. foetida were exposed to the chemical when placed in each jar containing $340 \mathrm{~g}$ of contaminated soil after evacuating their gut contents on moist filter paper for $3 \mathrm{~h}$ at $20^{\circ} \mathrm{C}$. The jars containing contaminated soil and worms were weighed, and the loss of water by evaporation was compensated for by adding distilled water every 2 days.

For the uptake experiment, worms were collected after exposure periods $(1,3,5,7,10,14,19,25$ and 32 days), rinsed with tap water and allowed to evacuate most of their gut contents on moist filter paper for $3 \mathrm{~h}$. The water on the surface of the worms was dried carefully with absorbent paper, and the worms were then weighed and frozen at $-20^{\circ} \mathrm{C}$ (in $50 \mathrm{~mL}$ polypropylene tubes). Soil samples $\left(6.8 \mathrm{~g}\right.$, wet weight) from each jar were also stored at $-20^{\circ} \mathrm{C}$. All the incubations were carried out on three replicates at each sample point.

For the elimination experiment, the $E$. foetida were transferred to clean soil after 14 days of exposure to contaminated soil. During the elimination period, worms were re-collected after 0.04, 0.13, $0.25,0.50,1,2$ and 4 days. After evacuating their gut contents and having their external water removed, the worms were stored at $-20^{\circ} \mathrm{C}$.

\subsection{Sample extraction and purification procedure}

All the samples were thawed for approximately $30 \mathrm{~min}$ at room temperature. Soil samples $(6.8 \mathrm{~g}$ per sample) were mixed with anhydrous sodium sulfate $(5.0 \mathrm{~g})$ and ethyl acetate $(25 \mathrm{~mL})$ in a $50 \mathrm{~mL}$ polypropylene centrifuge tube. The tubes were capped, vortex mixed for $3 \mathrm{~min}$, exposed to ultrasonic vibration (with a frequency of $40 \mathrm{kHz}$ and an ultrasonic power of $500 \mathrm{~W}$ ) for $20 \mathrm{~min}$ and then centrifuged at $3500 \mathrm{rpm}$ (approximately $1150 \times \mathrm{g}$ ) for $5 \mathrm{~min}$. The extraction was repeated again by following the same step. The combined extracts were filtered through anhydrous sodium sulfate $(5.0 \mathrm{~g})$ and evaporated to dryness on a rotary evaporator at $40^{\circ} \mathrm{C}$. The residue was reconstituted in acetonitrile $(2.0 \mathrm{~mL})$, and then PSA ( $40 \mathrm{mg}$ ) was added to the suspension for clean-up. After being shaken, the resulting solution was passed through a $0.22 \mu \mathrm{m}$ filter. A $0.1 \mathrm{~mL}$ aliquot of filtrate was taken and diluted to $1.0 \mathrm{~mL}$ with acetonitrile, and then the solution was analysed by HPLC-MS/MS.

For the E. foetida analysis, the samples ( $2.0 \mathrm{~g}$ per sample) were blended with ethyl acetate $(25 \mathrm{~mL})$ in a $50 \mathrm{~mL}$ polypropylene centrifuge tube. The mixture was homogenised with an Ultra-Turrax T18 homogeniser for $30 \mathrm{~s}$, vortex mixed for $3 \mathrm{~min}$, exposed to ultrasonic vibration (with a frequency of $40 \mathrm{kHz}$ and an ultrasonic power of $500 \mathrm{~W}$ ) for $20 \mathrm{~min}$ and then separated by centrifugation at $3500 \mathrm{rpm}$ (approximately $1150 \times g$ ) for $5 \mathrm{~min}$. The upper organic phase was passed through a funnel (medium-speed qualitative filter paper) with anhydrous sodium sulfate $(5.0 \mathrm{~g})$. The extraction was repeated again by following the same step. The combined extracts were evaporated to dryness at $40^{\circ} \mathrm{C}$. Next, the residue was reconstituted in acetonitrile $(5.0 \mathrm{~mL})$, and $n$-hexane $(3 \times 5.0 \mathrm{~mL})$ was then added for the liquid-liquid partition of the lipids. The upper layer of $n$-hexane was discarded, and the acetonitrile layer was evaporated to dryness by a rotary evaporator. The residue was diluted to $2.0 \mathrm{~mL}$ with acetonitrile. PSA ( $40 \mathrm{mg}$ ) and $\mathrm{C}_{18}$ (40 mg) were added to the resulting solution. The mixture was shaken and then passed through a filter membrane (pore size $0.22 \mu \mathrm{m}$ ). A $0.1 \mathrm{~mL}$ portion of the filtrate was taken and diluted to $1.0 \mathrm{~mL}$ with acetonitrile, and then the solution was analysed by HPLC-MS/MS.

\subsection{Chemical analysis}

HPLC-MS/MS analyses were performed using a Thermo Fisher Scientific (Waltham, MA) instrument equipped with an Accela 600 pump, an Accela autosampler and a Quantum Access triple quadrupole mass spectrometer (TSQ Quantum Access MAX) equipped with a heated electrospray ionisation (HESI) source working in selective reaction monitoring (SRM) mode in negative ionisation.

A Chiralcel OD-3R (4.6×150 mm i.d.; Daicel, Shanghai, China) column with a $3 \mu \mathrm{m}$ particle size was used at a flow rate of $400 \mu \mathrm{Lmin}^{-1}$ at $25^{\circ} \mathrm{C}$. Mobile phase A consisted of water/ ammonium formate $(10 \mathrm{mM})$, and mobile phase $B$ (acetonitrile) was a mixed-gradient programme starting at $45 \% A / 55 \% B$ and ending (32 $\mathrm{min}$ ) at $30 \% \mathrm{~A} / 70 \% \mathrm{~B}$. The injection volume was $5 \mu \mathrm{L}$.

The mass spectrometer and HESI source were used in negative-ion mode to determine the concentrations of fipronil and its metabolites. The parameters for the MS detector were as follows: negative mode; spray voltage $2200 \mathrm{~V}$; skimmer offset $0 \mathrm{~V}$; sheath gas pressure 40 arb.; auxiliary gas pressure 5 arb.; vaporiser temperature $250^{\circ} \mathrm{C}$; capillary temperature $350^{\circ} \mathrm{C}$; ion sweep gas pressure 0 arb. Table 1 lists the selective reaction monitoring (SRM) transitions used to identify and quantify the target analytes. Racemic fipronil and its metabolites were ideally baseline separated, and no enantiomerisation was observed for fipronil under these analytical conditions.

The external calibration curves were evaluated for S-fipronil, $R$-fipronil and metabolites (sulfide, sulfone and desulfinyl) within the $1-1000 \mathrm{ng} \mathrm{mL}^{-1}$ concentration range, and fipronil amide was evaluated in the $5-1000 \mathrm{ng} \mathrm{mL}^{-1}$ concentration range. According to the procedure described above, a blank matrix was prepared, and also a series of matrix-matched calibration standards with the same concentrations. The absolute recovery of fipronil and its metabolites was determined in the soil and E. foetida. A series of blank samples were fortified with rac-fipronil and its metabolites at four different concentration levels $\left(0.01,0.1,1.0\right.$ and $10 \mathrm{mg} \mathrm{kg}^{-1}$, 
Table 1. Characteristics of the HPLC-MS/MS method, LOD and LOQ employed for determining fipronil and metabolites

\begin{tabular}{|c|c|c|c|c|c|c|c|c|c|}
\hline Pesticides & $\begin{array}{c}t_{\mathrm{R}} \\
(\min )\end{array}$ & $\begin{array}{l}\text { Ionisation } \\
\text { mode }\end{array}$ & $\begin{array}{l}\text { Precursor } \\
\text { ion } \\
(m / z)\end{array}$ & $\begin{array}{c}\text { Product } \\
\text { ion } \\
(\mathrm{m} / \mathrm{z})^{\mathrm{a}}\end{array}$ & $\begin{array}{l}\text { Collision } \\
\text { energy } \\
\text { (V) }\end{array}$ & $\begin{array}{l}\text { Product } \\
\text { ion } \\
(m / z)^{b}\end{array}$ & $\begin{array}{l}\text { Collision } \\
\text { energy } \\
\text { (V) }\end{array}$ & $\begin{array}{c}\text { LOD } \\
\left(\mathrm{ng} \mathrm{g}^{-1}\right)\end{array}$ & $\begin{array}{c}\text { LOQ } \\
\left(\mathrm{ng} \mathrm{g}^{-1}\right)\end{array}$ \\
\hline S-Fipronil & 15.76 & - & 434.9 & 330.0 & 18 & 250.0 & 30 & 1.10 & 3.68 \\
\hline$R$-Fipronil & 16.71 & - & 434.9 & 330.0 & 18 & 250.0 & 30 & 1.10 & 3.68 \\
\hline Fipronil amide & 9.04 & - & 453.0 & 304.0 & 26 & 272.0 & 38 & 2.29 & 7.63 \\
\hline Fipronil sulfone & 18.92 & - & 450.9 & 415.0 & 18 & 282.0 & 29 & 0.32 & 1.06 \\
\hline Fipronil desulfinyl & 21.84 & - & 387.0 & 351.0 & 19 & 282.0 & 34 & 0.66 & 2.19 \\
\hline Fipronil sulfide & 29.19 & - & 418.9 & 262.0 & 30 & 383.0 & 16 & 0.89 & 2.98 \\
\hline
\end{tabular}

based on five replicates). The blank soil samples included $36 \%$ water, and the $E$. foetida individuals that had evacuated their gut contents were prepared the same way as the samples that were used in the $E$. foetida bioaccumulation experiment. The spiked blank samples were left for $1 \mathrm{~h}$ to ensure that the spiked pesticides were evenly distributed, and then extracted and determined as previously described. Recoveries were calculated by comparing the measured concentration with the fortified concentrations.

\subsection{Equilibrium partitioning model and data analysis}

Uptake of fipronil by $E$. foetida from the soils was described by the two-compartment model. ${ }^{33-35}$ The uptake kinetic parameters and the uptake curve were performed using the following model equations: ${ }^{36}$

$$
\begin{gathered}
\mathrm{d} C_{\text {worm }} / \mathrm{d} t=k_{1} C_{\text {soil }}-k_{2} C_{\text {worm }} \\
C_{\text {worm }}=\frac{k_{1} C_{\text {soil }}}{k_{2}}\left[1-\exp \left(-k_{2} t\right)\right]\left(0<t<t_{c}\right) \\
\mathrm{BAF}_{k}=\frac{k_{1}}{k_{2}}
\end{gathered}
$$

where $C_{\text {worm }}$ is the concentration of fipronil in earthworm tissues $\left(\mathrm{mg} \mathrm{kg}^{-1}\right), C_{\text {soil }}$ is the concentration of fipronil in the soil $\left(\mathrm{mg} \mathrm{kg}^{-1}\right)$, $k_{1}$ denotes the uptake rate constant from the soil $\left(\right.$ day $\left.^{-1}\right), k_{2}$ denotes the rate constant $\left(\right.$ day $\left.^{-1}\right)$ characterising the sum of the elimination, growth dilution and metabolic transformation of the two enantiomers in E. foetida and $t_{c}$ is the time (days) at the end of the uptake phase. The kinetic bioaccumulation factor $\left(\mathrm{BAF}_{k}\right)$ is defined as the ratio of the soil uptake rate constant $k_{1}$ to the elimination rate constant $k_{2}$.

When steady state is reached during the uptake phase (i.e. $t=\infty),{ }^{36}$ equation (2) may be reduced to

$$
\begin{gathered}
C_{\text {worm }}=\frac{k_{1}}{k_{2}} C_{\text {soil }} \\
\mathrm{BAF}_{k}=\frac{C_{\text {worm }}}{C_{\text {soil }}}=\frac{k_{1}}{k_{2}}
\end{gathered}
$$

The $C_{\text {worm }} / C_{\text {soil }}$ ratio is also defined as the bioaccumulation factor (BAF) under steady-state conditions in equation (5).

According equation (5), equation (2) is transformed into

$$
C_{\text {worm }}=\mathrm{BAF}_{k} \times C_{\text {soil }} \times\left[1-\exp \left(-k_{2} t\right)\right] \quad\left(0<t<t_{\mathrm{c}}\right)
$$

The $k_{1}$ uptake rate constant is calculated from $k_{2}$ (deriving from the depuration phase) and $\mathrm{BAF}_{k}$ (deriving from the uptake curve):

$$
k_{1}=\mathrm{BAF}_{k} \times k_{2}
$$

The bioaccumulation and biotransformation kinetics of the total fipronil (fipronil and its metabolites) in the soil and $E$. foetida were also fitted to the equilibrium partitioning model indicated above in equations (1) to (7). Here, $C_{\text {worm }}$ and $C_{\text {soil }}$ are the concentrations $\left(\mathrm{mg} \mathrm{kg}^{-1}\right)$ of total fipronil (fipronil and its metabolites) in the $E$. foetida and the soil respectively.

The enantiomer fraction (EF) was used as a measure of the enantioselective behaviours of fipronil during the experiment. The EF values ranged from 0 to 1 , with $E F=0.5$ representing the racemic mixture. The EF was defined by the following equation:

$$
\mathrm{EF}=\frac{C_{S}}{C_{S}+C_{R}}
$$

where $C_{S}$ is the concentration of $S$-fipronil and $C_{R}$ is the content of $R$-fipronil. A paired $t$-test was performed to compare the means of the $\mathrm{EF}$ values in the $E$. foetida and the soil samples with $\mathrm{EF}=0.5$.

\section{RESULTS AND DISCUSSION}

\subsection{Calibration and method validation}

Typical chromatograms of fipronil-fortified samples containing racemate and metabolite standard solutions are shown in supporting information Figure S1. Enantiomers of fipronil were baseline separated. There were no endogenous interference peaks at the same retention times as enantiomers of fipronil and metabolites. The matrix effect on the MS/MS (SRM) detector was investigated in the soil and E. foetida by comparing the standards in the solvent with the matrix-matched standards. A slight ion signal suppression for enantiomers of fipronil and metabolites was typically observed in this study, and the slope ratios (matrix-matched calibration/standard calibration in solvent) ranged from 0.842 to 0.967 . Thus, the ion suppression caused by the matrix would not affect the analysis of fipronil and its metabolites in the soil or $E$. foetida.

Good linear calibration curves were obtained over a $1-1000 \mathrm{ng} \mathrm{mL}^{-1}$ range for $S$-fipronil, $R$-fipronil, fipronil sulfide, fipronil sulfone and fipronil desulfinyl, and 5-1000 $\mathrm{ng} \mathrm{mL}^{-1}$ was used for fipronil amide. The average recoveries for enantiomers 
of fipronil and metabolites at levels between 0.01 and $10 \mathrm{mg} \mathrm{kg}^{-1}$ ranged between 89 and $99 \%$ in the soil and between 85 and $96 \%$ in earthworm tissues, with the relative standard deviations (RSDs) below $12 \%$ ( $n=5$ for each sample type). The limits of detection (LOD) and quantification (LOQ) for enantiomers of fipronil and metabolites were defined as the concentrations that gave signal-to-noise ratios of 3 and 10 (Table 1). The LOD and LOQ were estimated to be 1.10 and $3.68 \mathrm{ng} \mathrm{g}^{-1}$ for enantiomers of fipronil, 0.89 and $2.98 \mathrm{ng} \mathrm{g}^{-1}$ for fipronil sulfide, 0.32 and $1.06 \mathrm{ng} \mathrm{g}^{-1}$ for fipronil sulfone, 0.66 and $2.19 \mathrm{ng} \mathrm{g}^{-1}$ for fipronil desulfinyl and 2.29 and $7.63 \mathrm{ng} \mathrm{g}^{-1}$ for fipronil amide.

\subsection{Toxicity assay}

The analyses of fipronil racemate and enantiomers in the soil tests showed that the average measured concentrations were within $20 \%$ of the target concentrations. Fipronil racemate and individual enantiomers were not lethal to E. foetida at concentrations of $50-1000 \mathrm{mg} \mathrm{kg}^{-1}$ (soil). The surviving worms had reduced body weights, and their growth was inhibited. In some cases, these reductions could have been caused by changes in the physiological or biochemical processes of E. foetida, which resulted in reduced food intake and metabolism. ${ }^{37}$ The weights of $E$. foetida that were exposed to racemic fipronil and both enantiomers decreased with increasing concentration. The weights of the worms decreased to $38-62 \%$ ( $R$-fipronil), $23-53 \%$ (S-fipronil) and $30-57 \%$ (racemate) at concentrations of $1000-400 \mathrm{mg} \mathrm{kg}^{-1}$ in soil. The weights of the worms in the control decreased to $70-80 \%$ of initial mass. The E. foetida in spiked soil treated with a lower concentration of fipronil lost less body weight than worms at higher concentrations in comparison with the $E$. foetida in the control. The slope intervals for racemate, $S$-enantiomer and $R$-enantiomer were $-0.0531 \pm 0.00585,-0.0561 \pm 0.00864$ and $-0.0398 \pm 0.00399$ respectively (Fig. 2 ). The $R$-fipronil slope was lower than the slopes of racemate and $S$-fipronil, implying lower toxicity of $R$-fipronil for earthworm growth. For subchronic exposures, the $R$-enantiomer had the lowest toxicity compared with racemate and the $S$-enantiomer. The toxicity of the racemate and S-enantiomer exhibited no differences. The same enantioselective subchronic toxicity was observed in the growth of juvenile fathead minnows (Pimephales promelas) that were exposed to fipronil-spiked sediment. ${ }^{38}$

\subsection{Transformation and persistence in the soil}

Enantiomers of fipronil and metabolites in earthworm tissues and soils were determined (Figs 3 and 4). At the end of the exposure ( 32 days), the concentrations in soil decreased $10-30 \%$ for enantiomers of fipronil at different exposures (Fig. 3). The losses may be due to degradation, volatilisation or biotransformation, or to a combination of these processes. The residues were present primarily in the form of the parent compound and metabolites such as amide, sulfone and sulfide. Desulfinyl metabolite residues were not detected in the soil. The desulfinyl metabolite could have been produced by photolysis. ${ }^{16,19}$ Soil samples were not directly exposed to sunlight, which could be one reason why desulfinyl was not produced over the course of the experiment. The fipronil EF values in the soil samples remained largely unchanged (Fig. 5), and no significant difference was observed between the two enantiomers at different exposures ( 20 and $50 \mathrm{mg} \mathrm{kg}^{-1}$ ).

\subsection{Bioaccumulation and elimination in Eisenia foetida}

The concentrations of enantiomers of fipronil in exposed $E$. foetida increased on day 1, as shown in Fig. 3. A higher rate of fipronil

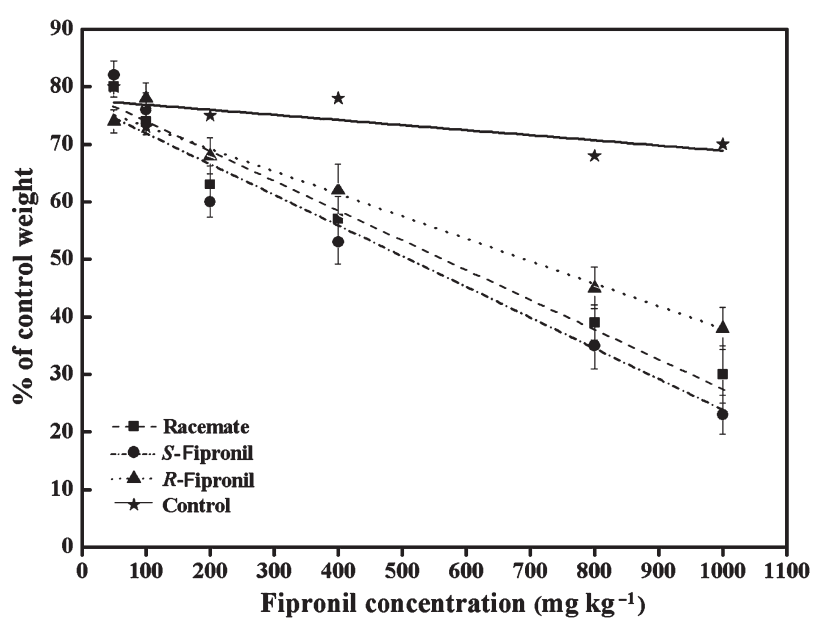

Figure 2. Concentration-response relation for the growth of Eisenia foetida exposed to fipronil racemate, $S$-fipronil and $R$-fipronil. Error bars are the standard deviations of the means of toxicity tests on three replicates. The control was acetone, which was the solvent for the enantiomers of fipronil.

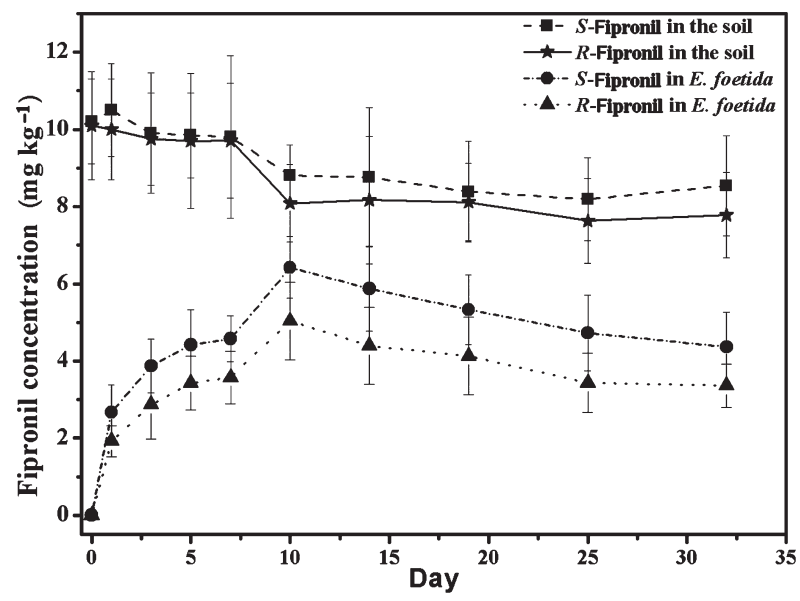

Figure 3. The concentrations of enantiomers of fipronil of $20 \mathrm{mg} \mathrm{kg}^{-1}$ rac-fipronil treatments in the soil and Eisenia foetida. Error bars are the standard deviations of the means of bioaccumulation tests on three replicates.

application resulted in higher residues, and the concentrations of the two enantiomers reached their highest level on day 10 . The concentrations exhibited a slight decline from day 14 to day 32, which may have been explained by the declining concentration in the soil. In addition, a concentration difference was observed between the two enantiomers in earthworm tissues at the same sample point, and S-fipronil had a higher concentration than $R$-fipronil as the duration of exposure increased. As shown in Fig. 5, the EF values in earthworm tissues deviated from 0.50 $(P<0.001)$ in the bioaccumulation experiment, and they were maintained at approximately $0.56-0.62$. A paired $t$-test for the same time points between the EF values of spiked soil and the $\mathrm{EF}$ values of $E$. foetida yielded a $P$-value of $<0.001$. Therefore, enantioselectivity occurred when the two enantiomers of fipronil were bioaccumulated by E. foetida.

Metabolites of fipronil, such as sulfone and sulfide (Fig. 4), were detected in earthworm tissues, but the concentration of fipronil amide was low. Fipronil metabolites reached their highest level between day 7 and day 14, and the concentrations of fipronil 

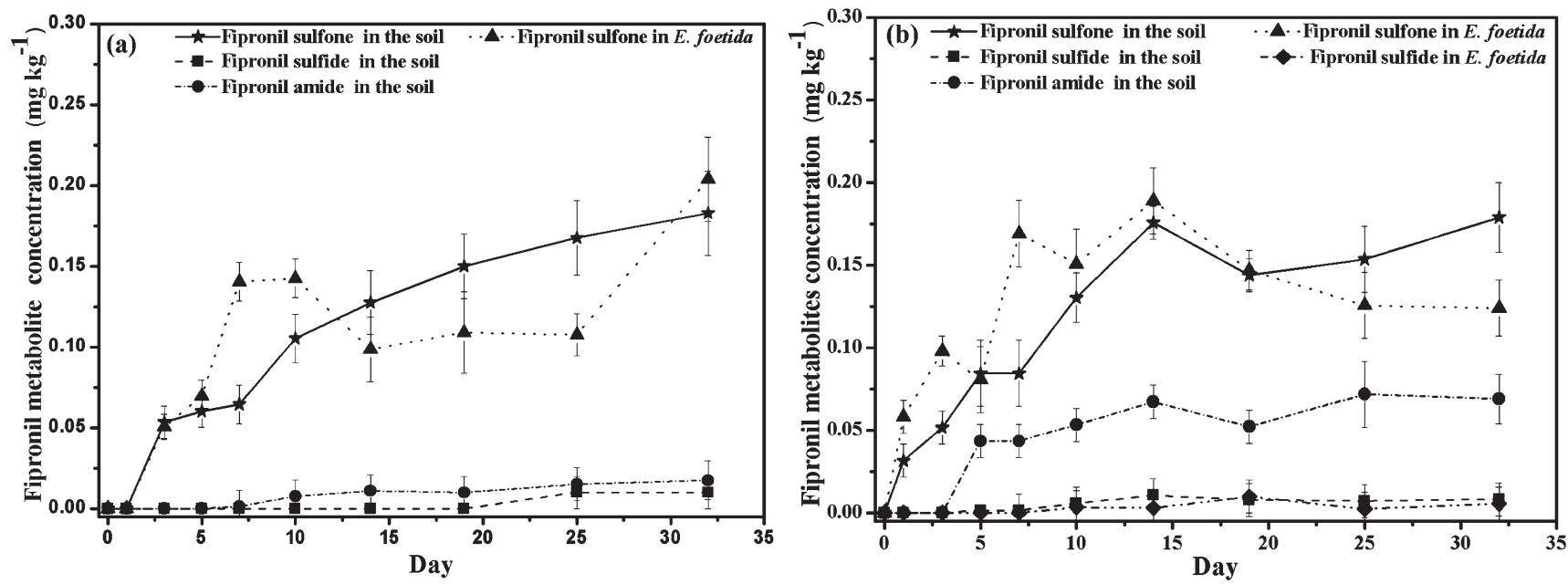

Figure 4. The concentrations of fipronil metabolites in the soil and Eisenia foetida: (a) $10 \mathrm{mg} \mathrm{kg}^{-1}$ of S-fipronil; (b) $10 \mathrm{mg} \mathrm{kg}^{-1}$ of $R$-fipronil. Error bars are the standard deviations of the means of bioaccumulation tests on three replicates.

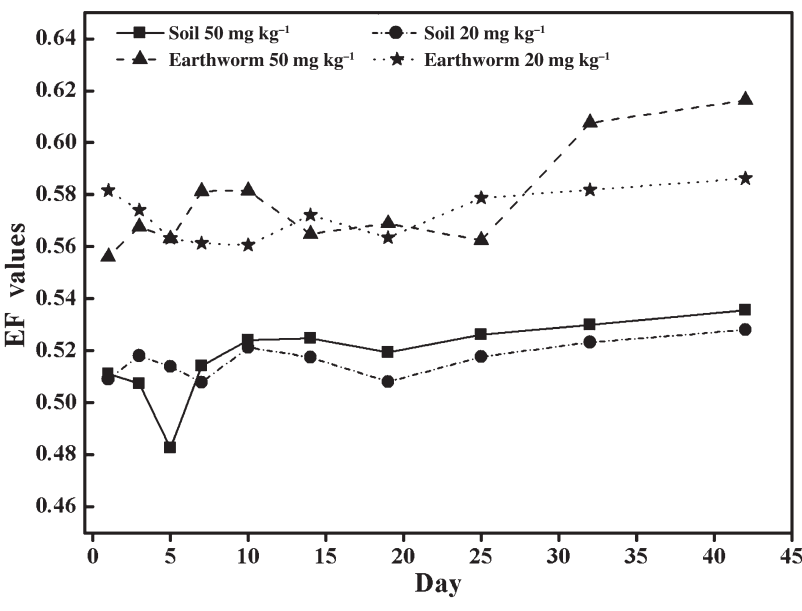

Figure 5. Enantiomeric fraction (EF) of fipronil in the soil and Eisenia foetida by sampling days.

sulfone in worms were higher than the concentrations of fipronil sulfide (in the soil or E. foetida) and sulfone (in the soil) from day 7 to day 32 at rac-fipronil exposures of 20 and $50 \mathrm{mg} \mathrm{kg}^{-1}$. In comparison with the soil, the concentrations of fipronil amide in earthworm tissues were lower throughout the exposure period. Based on the concentrations of the individual fipronil enantiomers, no enantiomerisation was observed for fipronil. The concentrations of S-fipronil were always higher than those of $R$-fipronil, and the residue of total fipronil metabolites in the S-enantiomer was less than that of the $R$-enantiomer in both the soil and E. foetida at the given exposure levels of the individual fipronil enantiomers. Therefore, $S$-fipronil was preferentially accumulated, and $R$-fipronil might have been previously metabolised into fipronil metabolites under laboratory conditions.

In this work, the biota-to-soil accumulation factor (BSAF) was used to express the bioaccumulation of fipronil and its metabolites in earthworm tissues. BSAF was a function of the relative sorptive capacities of the organism versus the surrounding environment, and the activities in this work were normalised to the lipid content of the earthworms and the organic carbon $(\mathrm{OC})$ in the soil. A lipid content of $1 \%{ }^{24,34}$ and a factor of 1.7 between the organic carbon
$(\mathrm{OC})$ and organic matter $(\mathrm{OM})^{39}$ were assumed. The BSAF was defined as follows:

$$
\begin{gathered}
\text { BSAF ( } \left.\mathrm{kg} \text { dry weight } \mathrm{kg}^{-1} \text { wet weight }\right)=\frac{C_{\text {worm }}}{C_{\text {soil }}} \\
\operatorname{BSAF}\left(\mathrm{kg}_{\mathrm{OC}} \mathrm{kg}_{\text {lip }}^{-1}\right)=\frac{C_{\text {worm }} F_{\text {OM }}}{1.7 C_{\text {soil }} F_{\text {lip }}}
\end{gathered}
$$

where $C_{\text {worm }}$ and $C_{\text {soil }}$ are the concentrations of enantiomers of fipronil or metabolites in $E$. foetida and the soil respectively, $F_{\mathrm{OM}}$ (soil) is the fraction of organic matter in the soil and $F_{\text {lip }}$ (earthworm) is the fraction of lipids in the earthworms. The BSAF values of enantiomers of fipronil (Table 2) reached their highest level on day 10, and the BSAF values for the metabolites reached their highest level between day 7 and day 14. A paired $t$-test for the same time points between $S$-fipronil and $R$-fipronil yielded $P$-values of less than 0.05 at rac-fipronil exposures of 20 and $50 \mathrm{mg} \mathrm{kg}^{-1}$. The paired $t$-test showed that there was a significant difference in the BSAFs between the two enantiomers of fipronil. The BSAF values for S-fipronil were larger than those for $R$-fipronil, indicating that $S$-fipronil was preferentially accumulated over $R$-fipronil in earthworm tissues. E. foetida take up organic chemicals through their skin in addition to their gut wall. ${ }^{40}$ Thus, it can be assumed that enantiomers of fipronil in earthworm tissues accumulated via skin exposure and gut absorption were enantioselective. The same bioaccumulation phenomena for benalaxyl, metalaxyl, tebuconazole and alpha-cypermethrin were observed in spiked soil. ${ }^{24-26,40} \mathrm{~A}$ paired $t$-test for the same time points among the fipronil metabolites sulfide, sulfone and amide at different exposures yielded $P$-values that were all less than 0.05 , except when they were between sulfide and amide $(P=0.343)$ at $10 \mathrm{mg} \mathrm{kg}^{-1}$ (S-fipronil). The BSAF values revealed a significant difference among fipronil metabolites. Earthworm tissues exhibited a relative enrichment of fipronil sulfide and sulfone, and decreased weight gain in worms was linked to fipronil amide. This finding was also confirmed by the fact that much less lipophilic fipronil amide than sulfide and sulfone could be transferred and bioaccumulated in E. foetida.

Armitage and Gobas $^{35}$ tested the model for the soilearthworm-shrew food chain and noted (i) that chemicals 


\begin{tabular}{|c|c|c|c|c|c|c|}
\hline $\begin{array}{l}\text { Exposure time } \\
\text { (days) }\end{array}$ & $\begin{array}{c}\text { Exposure level } \\
\left(\mathrm{kg}_{\mathrm{oc}} \mathrm{kg}_{\text {lip }}^{-1}\right)\end{array}$ & S-Fipronil & $R$-Fipronil & Fipronil sulfone & Fipronil sulfide & Fipronil amide \\
\hline \multirow[t]{4}{*}{1} & rac-Fipronil (50) & $0.577 \pm 0.039$ & $0.492 \pm 0.133$ & $2.640 \pm 0.247$ & $1.259 \pm 0.180$ & ND \\
\hline & rac-Fipronil (20) & $0.490 \pm 0.151$ & $0.374 \pm 0.125$ & $3.880 \pm 0.384$ & $0.529 \pm 0.121$ & ND \\
\hline & S-Fipronil (10) & $0.407 \pm 0.123$ & ND & ND & ND & ND \\
\hline & R-Fipronil (10) & ND & $0.411 \pm 0.086$ & $3.830 \pm 1.856$ & ND & ND \\
\hline \multirow[t]{4}{*}{3} & rac-Fipronil (50) & $0.638 \pm 0.119$ & $0.496 \pm 0.102$ & $1.462 \pm 0.194$ & $1.024 \pm 0.161$ & ND \\
\hline & rac-Fipronil (20) & $0.766 \pm 0.258$ & $0.556 \pm 0.151$ & $1.840 \pm 0.233$ & $1.052 \pm 0.582$ & ND \\
\hline & S-Fipronil (10) & $0.464 \pm 0.206$ & ND & $1.785 \pm 0.016$ & ND & ND \\
\hline & $R$-Fipronil (10) & ND & $0.430 \pm 0.146$ & $3.665 \pm 0.683$ & ND & ND \\
\hline \multirow[t]{4}{*}{5} & rac-Fipronil (50) & $1.023 \pm 0.214$ & $0.730 \pm 0.001$ & $1.925 \pm 0.241$ & $0.845 \pm 0.146$ & $0.020 \pm 0.007$ \\
\hline & rac-Fipronil (20) & $0.842 \pm 0.079$ & $0.693 \pm 0.250$ & $1.912 \pm 0.276$ & $1.127 \pm 0.537$ & ND \\
\hline & S-Fipronil (10) & $0.880 \pm 0.165$ & ND & $2.258 \pm 0.698$ & ND & ND \\
\hline & R-Fipronil (10) & ND & $0.713 \pm 0.164$ & $1.920 \pm 0.892$ & ND & ND \\
\hline \multirow[t]{4}{*}{7} & rac-Fipronil (50) & $1.492 \pm 0.267$ & $1.127 \pm 0.174$ & $1.951 \pm 0.432$ & $0.850 \pm 0.163$ & $0.080 \pm 0.049$ \\
\hline & rac-Fipronil (20) & $0.921 \pm 0.301$ & $0.722 \pm 0.246$ & $2.264 \pm 0.471$ & $1.170 \pm 0.384$ & ND \\
\hline & S-Fipronil (10) & $0.960 \pm 0.136$ & ND & $4.232 \pm 0.963$ & ND & ND \\
\hline & $R$-Fipronil (10) & ND & $0.766 \pm 0.169$ & $4.009 \pm 1.437$ & ND & ND \\
\hline \multirow[t]{4}{*}{10} & rac-Fipronil (50) & $1.759 \pm 0.095$ & $1.402 \pm 0.276$ & $4.856 \pm 0.518$ & $1.294 \pm 0.111$ & $0.209 \pm 0.198$ \\
\hline & rac-Fipronil (20) & $1.391 \pm 0.247$ & $1.209 \pm 0.386$ & $2.341 \pm 0.234$ & $1.887 \pm 0.491$ & ND \\
\hline & S-Fipronil (10) & $1.255 \pm 0.230$ & ND & $3.356 \pm 2.271$ & ND & ND \\
\hline & $R$-Fipronil (10) & ND & $1.099 \pm 0.282$ & $2.471 \pm 1.097$ & $1.072 \pm 0.145$ & ND \\
\hline \multirow[t]{4}{*}{14} & rac-Fipronil (50) & $1.366 \pm 0.149$ & $1.166 \pm 0.257$ & $6.027 \pm 0.718$ & $1.710 \pm 0.345$ & $0.092 \pm 0.069$ \\
\hline & rac-Fipronil (20) & $1.325 \pm 0.493$ & $1.013 \pm 0.027$ & $3.275 \pm 0.534$ & $2.103 \pm 0.345$ & ND \\
\hline & S-Fipronil (10) & $1.216 \pm 0.286$ & ND & $1.503 \pm 0.504$ & ND & ND \\
\hline & $R$-Fipronil (10) & ND & $1.149 \pm 0.161$ & $2.040 \pm 0.282$ & $1.028 \pm 1.116$ & ND \\
\hline \multirow[t]{4}{*}{19} & rac-Fipronil (50) & $1.365 \pm 0.135$ & $1.118 \pm 0.171$ & $4.558 \pm 1.066$ & $1.726 \pm 0.400$ & $0.134 \pm 0.074$ \\
\hline & rac-Fipronil (20) & $1.212 \pm 0.212$ & $0.980 \pm 0.291$ & $2.682 \pm 0.489$ & $2.106 \pm 0.767$ & ND \\
\hline & S-Fipronil (10) & $1.440 \pm 0.504$ & ND & $1.446 \pm 0.731$ & ND & ND \\
\hline & $R$-Fipronil (10) & ND & $1.092 \pm 0.174$ & $1.948 \pm 0.523$ & $2.415 \pm 0.655$ & ND \\
\hline \multirow[t]{4}{*}{25} & rac-Fipronil (50) & $1.274 \pm 0.327$ & $1.103 \pm 0.319$ & $2.842 \pm 0.775$ & $1.602 \pm 0.434$ & $0.106 \pm 0.076$ \\
\hline & rac-Fipronil (20) & $1.091 \pm 0.195$ & $0.881 \pm 0.319$ & $2.015 \pm 0.246$ & $1.320 \pm 0.145$ & ND \\
\hline & S-Fipronil (10) & $1.171 \pm 0.305$ & ND & $1.221 \pm 0.312$ & ND & ND \\
\hline & $R$-Fipronil (10) & ND & $1.088 \pm 0.353$ & $1.555 \pm 0.241$ & $0.617 \pm 0.458$ & ND \\
\hline \multirow[t]{4}{*}{32} & rac-Fipronil (50) & $1.350 \pm 0.273$ & $0.995 \pm 0.392$ & $3.142 \pm 0.359$ & $2.366 \pm 0.461$ & $0.068 \pm 0.039$ \\
\hline & rac-Fipronil (20) & $0.990 \pm 0.281$ & $0.815 \pm 0.021$ & $2.320 \pm 0.575$ & $1.592 \pm 0.705$ & $\mathrm{ND}$ \\
\hline & S-Fipronil (10) & $1.163 \pm 0.504$ & ND & $2.213 \pm 0.823$ & ND & ND \\
\hline & $R$-Fipronil (10) & ND & $0.640 \pm 0.246$ & $1.314 \pm 0.282$ & $1.475 \pm 0.532$ & ND \\
\hline
\end{tabular}

with an octanol-air partition coefficient $\left(K_{\mathrm{OA}}\right)$ of $<10^{5.25}$ did not biomagnify, and (ii) that chemicals with $K_{\mathrm{OA}} \geq 10^{5.25}$ and an octanol-water partition coefficient $\left(K_{\text {ow }}\right)$ between $10^{1.75}$ and $10^{12}$ had biomagnification potential unless they were metabolised at a sufficiently rapid rate. The $K_{\mathrm{OW}}{ }^{13}$ for fipronil was $5.62 \times 10^{3}$, and the $K_{\mathrm{OA}}$ was $3.51 \times 10^{10}\left(>10^{5}\right)$, as calculated by the following equation:

$$
K_{\mathrm{OA}}=\frac{K_{\mathrm{OW}}}{H}
$$

where $H$ is Henry's law constant at room temperature. Given the $K_{\mathrm{OW}}$ and the $K_{\mathrm{OA}}$ values, fipronil was expected to have biomagnification potential in the earthworm food chain according to this theory.

In the elimination experiments, E. foetida were transferred to fipronil-free soil without contacting and feeding on fipronil-spiked soil. The quantity of fipronil and metabolite residues in the tissues decreased significantly within 4 days. The depuration of enantiomers of fipronil in E. foetida fitted first-order kinetics (Table 3). The half-life $\left(T_{1 / 2}\right)$ of $R$-fipronil in E. foetida ranged from 1.2 to 2.0 days, and from 1.5 to 2.1 days for $S$-fipronil. This finding indicated that the degradation of fipronil in E. foetida was enantioselective, and $S$-fipronil was more persistent than $R$-fipronil.

\subsection{Kinetic analysis}

To evaluate the validity of the equilibrium partitioning model, tests were conducted to determine whether the temporal course of fipronil uptake into E. foetida that were exposed to soil could be described by equations (6) and (7). The average concentrations of each enantiomer and total fipronil (fipronil and metabolites) in $E$. foetida and the soil at four exposure levels for the corresponding time points were fitted to equation (6) by using the non-linear regression function in SPSS 16.0 (SPSS Inc., Chicago, IL). Non-linear dynamic fitting yielded an estimated value of $\mathrm{BAF}_{k}$. The uptake 
Table 3. The elimination equation and half-life $\left(T_{1 / 2}\right)$ of enantiomers of fipronil in Eisenia foetida

\begin{tabular}{|lllll|}
\hline Exposure group & Enantiomers & Elimination equation & $T_{1 / 2}$ (days) & Correlation coefficient \\
\hline $50 \mathrm{mg} \mathrm{kg}^{-1}$ of rac-fipronil & S-Fipronil & $C_{\text {worm }}=7.969 \mathrm{e}^{-0.325 t}$ & 2.133 & 0.951 \\
& $R$-Fipronil & $C_{\text {worm }}=7.219 \mathrm{e}^{-0.345 t}$ & 2.009 & 0.930 \\
& Total fipronil & $C_{\text {worm }}=16.26 \mathrm{e}^{-0.352 t}$ & 1.969 & 0.928 \\
$20 \mathrm{mg} \mathrm{kg}^{-1}$ of rac-fipronil & S-Fipronil & $C_{\text {worm }}=4.905 \mathrm{e}^{-0.401 t}$ & 1.728 & 0.965 \\
& $R$-Fipronil & $C_{\text {worm }}=3.933 \mathrm{e}^{-0.456 t}$ & 1.520 & 0.989 \\
& Total fipronil & $C_{\text {worm }}=9.679 \mathrm{e}^{-0.439 t}$ & 1.579 & 0.984 \\
$10 \mathrm{mg} \mathrm{kg}^{-1}$ of S-fipronil & S-Fipronil & $C_{\text {worm }}=3.757 \mathrm{e}^{-0.466 t}$ & 1.487 & 0.888 \\
& Total fipronil & $C_{\text {worm }}=3.800 \mathrm{e}^{-0.470 t}$ & 1.475 & 0.886 \\
$10 \mathrm{mg} \mathrm{kg}^{-1}$ of $R$-fipronil & $R$-Fipronil & $C_{\text {worm }}=3.864 \mathrm{e}^{-0.539 t}$ & 1.286 & 0.988 \\
& Total fipronil & $C_{\text {worm }}=4.034 \mathrm{e}^{-0.447 t}$ & 1.551 & 0.961 \\
\hline a Including enantiomers of fipronil and metabolites. & & & \\
\hline
\end{tabular}

Table 4. The uptake rate coefficient $\left(k_{1}\right)$, elimination rate coefficient $\left(k_{2}\right)$, kinetic bioaccumulation factor $\left(\mathrm{BAF}_{k}\right)$ and correlation coefficient $(r)$ of enantiomers of fipronil and total fipronil at different exposures

\begin{tabular}{|c|c|c|c|c|c|}
\hline Exposure group & Enantiomers & $\mathrm{BAF}_{k}$ & $k_{1}$ & $k_{2}$ & $r$ \\
\hline \multirow[t]{3}{*}{$50 \mathrm{mg} \mathrm{kg}^{-1}$ of rac-fipronil } & S-Fipronil & 0.746 & 0.242 & 0.325 & 0.895 \\
\hline & $R$-Fipronil & 0.581 & 0.200 & 0.345 & 0.871 \\
\hline & Total fipronila & 0.639 & 0.225 & 0.352 & 0.897 \\
\hline \multirow[t]{3}{*}{$20 \mathrm{mg} \mathrm{kg}^{-1}$ of rac-fipronil } & S-Fipronil & 0.593 & 0.237 & 0.401 & 0.922 \\
\hline & $R$-Fipronil & 0.465 & 0.212 & 0.456 & 0.896 \\
\hline & Total fipronil & 0.545 & 0.239 & 0.439 & 0.914 \\
\hline \multirow[t]{2}{*}{$10 \mathrm{mg} \mathrm{kg}^{-1}$ of $S$-fipronil } & S-Fipronil & 0.577 & 0.269 & 0.466 & 0.894 \\
\hline & Total fipronil & 0.583 & 0.274 & 0.470 & 0.898 \\
\hline \multirow[t]{2}{*}{$10 \mathrm{mg} \mathrm{kg}^{-1}$ of $R$-fipronil } & $R$-Fipronil & 0.467 & 0.251 & 0.539 & 0.812 \\
\hline & Total fipronil & 0.492 & 0.220 & 0.447 & 0.851 \\
\hline
\end{tabular}

rate constant $k_{1}$ was calculated using equation (7). The regression results are shown in Table 4.

The model was suitable for describing the uptake kinetics of $S$-fipronil, $R$-fipronil and total fipronil at different exposures, as indicated by high coefficients of correlation $(r=0.894-0.922$, $r=0.812-0.896$ and $r=0.851-0.914$ respectively). Uptake of enantiomers of fipronil in E. foetida fitted first-order kinetics and was accumulated from the soil in what was primarily an equilibrium partition process. The elimination rate coefficient $\left(k_{2}\right)$ for the bioaccumulation model was accurately determined by the depuration processes and was $0.33-0.47$ for S-fipronil and 0.35-0.54 for $R$-fipronil. The approximation uptake rate constant $k_{1}$ was $0.24-0.27$ for $S$-fipronil and $0.20-0.25$ for $R$-fipronil. The uptake rate coefficients $\left(k_{1}\right)$ of $S$-fipronil were all higher than the rates for $R$-fipronil. In addition, the elimination rate coefficients $\left(k_{2}\right)$ of $R$-fipronil were higher than those of $S$-fipronil. Rate constants $\mathrm{BAF}_{k}$ for $S$-fipronil and $R$-fipronil were less than 1.0, amounting to $0.58-0.75$ and $0.47-0.58$ respectively. This result indicated that the uptake rate that represented the motive power of accumulation in E. foetida was low when compared with the rate of elimination and metabolism. The accumulation, degradation and elimination of fipronil in earthworm tissues was enantioselective. $S$-Fipronil was preferentially accumulated, and $R$-fipronil might have been eliminated or metabolised.

\section{CONCLUSION}

In this study, the enantioselective subchronic toxicity and bioaccumulation of fipronil at four exposure levels (racemate 20 and $50 \mathrm{mg} \mathrm{kg}^{-1}$, individual enantiomers $10 \mathrm{mg} \mathrm{kg}^{-1}$ ) were assayed by soil contaminant. The results showed that $R$-fipronil was less toxic than racemate and S-fipronil to the non-target organism $E$. foetida, and there was a significant trend towards enantioselective bioaccumulation in E. foetida, with a preferential accumulation of $S$-fipronil (EF at $0.56-0.62, P<0.001$ ). The present study demonstrated the fate of fipronil and potential exposures in a simplified soil-earthworm system. The worms accumulated fipronil, fipronil sulfide and sulfone. In addition, the amount of fipronil amide was relatively low in earthworm tissues. Enantiomers of fipronil and metabolites (sulfone and sulfide) might be subject to a biomagnifying effect in the earthworm food chain. Although the present study demonstrated the variable fate of fipronil in the terrestrial environment, more research on the toxicity of fipronil sulfide and sulfone metabolites to non-target organisms should be investigated. Moreover, higher animals and variable levels of exposure should be employed for a more precise risk assessment in terrestrial food webs for future research.

\section{ACKNOWLEDGEMENTS}

This project was supported by the National High Technology Research and Development Programme (863) of China (No. 
2012AA06A302) and the National Natural Science Foundation of China (Nos 21277163 and 41301569).

\section{SUPPORTING INFORMATION}

Supporting information may be found in the online version of this article.

\section{REFERENCES}

1 Chaton PF, Ravanel P, Tissut M and Meyran JC, Toxicity and bioaccumulation of fipronil in the nontarget arthropodan fauna associated with subalpine mosquito breeding sites. Ecotoxicol Environ Saf 52:8-12 (2002).

2 Aajoud A, Ravanel P and Tissut M, Fipronil metabolism and dissipation in a simplified aquatic ecosystem. J Agric Food Chem 51:1347-1352 (2003).

3 Teicher HB, Kofoed-Hansen B and Jacobsen N, Insecticidal activity of the enantiomers of fipronil. Pest Manag Sci 59:1273-1275 (2003).

4 Liu DH, Wang P, Zhu WD, Gu X, Zhou WF and Zhou ZQ, Enantioselective degradation of fipronil in Chinese cabbage (Brassica pekinensis). Food Chem 110:399-405 (2008).

5 Konwick BJ, Fisk AT, Garrison AW, Avants JK and Black MC, Acute enantioselective toxicity of fipronil and its desulfinyl photoproduct to Ceriodaphnia dubia. Environ Toxicol Chem 24:2350-2355 (2005).

6 Overmyer JP, Rouse DR, Avants JK, Garrison AW, Delorenzo ME, Chung KW et al., Toxicity of fipronil and its enantiomers to marine and freshwater non-targets. J Environ Sci HIth Part B 42:471 -480 (2007).

7 Wilson WA, Konwick BJ, Garrison AW, Avants JK and Black MC, Enantioselective chronic toxicity of fipronil to Ceriodaphnia dubia. Arch Environ Contam Toxicol 54:36-43 (2008).

8 Nillos MG, Lin K, Gan J, Bondarenko S and Schlenk D, Enantioselectivity in fipronil aquatic toxicity and degradation. Environ Toxicol Chem 28:1825-1833 (2009).

9 Jones WJ, Mazur CS, Kenneke JF and Garrison AW, Enantioselective microbial transformation of the phenylpyrazole insecticide fipronil in anoxic sediments. Environ Sci Technol 41:8301 - 8307 (2007).

10 Lu DH, Liu DH, Gu X, Diao JL and Zhou ZQ, Stereoselective metabolism of fipronil in water hyacinth (Eichhornia crassipes). Pestic Biochem Physiol 97:289-293 (2010).

11 Liu TT, Wang P, Lu YL, Zhou GX, Diao JL and Zhou ZQ, Enantioselective bioaccumulation of soil-associated fipronil enantiomers in Tubifex tubifex. J Hazard Mater 219-220:50-56 (2012).

12 Raveton M, Aajoud A, Willison J, Cherifi M, Tissut M and Ravanel P, Soil distribution of fipronil and its metabolites originating from a seed-coated formulation. Chemosphere 69:1124-1129 (2007).

13 The University of Hertfordshire's Agricultural Substance Databases. [Online]. (2014). Available: http://sitem.herts.ac.uk/aeru /iupac/ [09 July 2014].

14 Tomlin C, The e-Pesticide Manual, 12th edition. British Crop Protection Council, Farnham, UK (2000).

15 Kumar R, Singh B, Mandal K, Kar A and Sarao PS, Bioefficacy and fate of fipronil and its metabolites in basmati rice under sub-tropical climatic conditions. Crop Prot 45:41 - 48 (2013).

16 Hainzl D and Casida JE, Fipronil insecticides: novel photochemical desulfinylation with retention of neurotoxicity. Proc Natl Acad SciUSA 93:12 764-12 767 (1996).

17 Bobé A, Cooper JF, Coste CM and Muller MA, Behaviour of fipronil in soil under Sahelian Plain field conditions. Pestic Sci 52:275-281 (1998).

18 Ramesh A and Balasubramanian M, Kinetics and hydrolysis of fenamiphos, fipronil and trifluralin in aquous buffer solutions. J Agric Food Chem 47:3367-3371 (1999).

19 Bobé A, Meallier P, Cooper JF and Coste CM, Kinetics and mechanisms of abiotic degradation of fipronil (hydrolysis and photolysis). J Agric Food Chem 46:2834-2839 (1998).

20 Ngim KK and Crosby DG, Abiotic processes influencing fipronil and desthiofipronil dissipation in California, USA, rice fields. Environ Toxicol Chem 20:972-977 (2001).
21 Klein R and Paulus M, Umweltproben für die Schadstoffanalytik im Biomonitoring. Gustav Fischer Verlag, Jena/Stuttgart, Germany, pp. 183-202 (1995).

22 Abdul Rida AMM and Bouché MB, Heavy metal linkages with mineral, organic and living soil compartments. Soil Biol Biochem 29:649-655(1997).

23 Paoletti GM, The role of earthworms for assessment of sustainability and as bioindicators. Agric Ecosyst Environ 74:137-155 (1999).

24 Xu P, Diao JL, Liu DH and Zhou ZQ, Enantioselective bioaccumulation and toxic effects of metalaxyl in earthworm Eisenia foetida. Chemosphere 83:1074-1079 (2011).

25 Yu DY, Li JZ, Zhang YF, Wang HL, Guo BY and Zheng L, Enantioselective bioaccumulation of tebuconazole in earthworm Eisenia foetida. J Environ Sci 24:2198-2204 (2012).

26 Diao JL, Xu P, Liu DH, Lu YL and Zhou ZQ, Enantiomer-specific toxicity and bioaccumulation of alpha-cypermethrin to earthworm Eisenia foetida. J Hazard Mater 192:1072-1078 (2011).

27 Mostert MA, Schoeman AS and Van der Merwe M, The relative toxicities of insecticides to earthworms of the Pheretima group (Oligochaeta). Pest Manag Sci 58:446-450 (2002).

28 Alves PRL, Cardoso EJBN, Martines AM, Sousa JP and Pasini A, Earthworm ecotoxicological assessments of pesticides used to treat seeds under tropical conditions. Chemosphere 90:2674-2682 (2013).

29 Sellström U, De Wit CA, Lundgren N and Tysklind M, Effect of sewage-sludge application on concentrations of higher-brominated diphenyl ethers in soils and earthworms. Environ Sci Technol 39:9064-9070 (2005).

30 Tian Q, Chiral pesticide separation and analysis, studied on polysaccharide-based chiral stationary phase under reversed phase conditions. Doctoral Dissertation, China Agricultural University, Beijing, China (2007).

31 Tian Q, Lv CG, Wang P, Ren LP, Qiu J, Li L et al., Enantiomeric separation of chiral pesticides by high performance liquid chromatography on cellulose tris-3,5-dimethyl carbamate stationary phase under reversed phase conditions. J Sep Sci 30:310-321 (2007).

32 Tian Q, Bi CL, Ren LP, Wang LP and Zhou ZQ, The application of high performance liquid chromatography with circular dichroism detector in the chiral compounds. Chin J Anal Chem 34:427-432 (2006).

33 Connell DW and Markwell RD, Bioaccumulation in the soil to earthworm system. Chemosphere 20:91-100 (1990).

34 Krauss M, Wilcke W and Zech W, Availability of polycyclic aromatic hydrocarbons (PAHs) and polychlorinated biphenyls (PCBs) to earthworms in urban soils. Environ Sci Technol 34:4335-4340 (2000).

35 Armitage JM and Gobas FAPC, A terrestrial food-chain bioaccumulation model for POPs. Environ Sci Technol 41:4019-4025 (2007).

36 Wang HL, Chen JH, Guo BY and Li JZ, Enantioseletive bioaccumulation and metabolization of diniconazole in earthworms (Eisenia foetida) in an artificial soil. Ecotoxicol Environ Saf 99:98-104 (2014).

37 Ribeiro S, Sousa JP and Nogueira AJA, Effect of endosulfan and parathion on energy reserves and physiological parameters of the terrestrial isopod Porcellio dilatatus. Ecotoxicol Environ Saf 49:131-138 (2001).

38 Baird S, Garrison A, Jones J, Avants J, Bringolf R and Black M, Enantioselective toxicity and bioaccumulation of fipronil in fathead minnows (Pimephales promelas) following water and sediment exposures. Environ Toxicol Chem 32:222-227 (2013).

39 Jager T, Fleuren RHLJ, Hogendoorn EA and De Korte G, Elucidating the routes of exposure for organic chemicals in the earthworm, Eisenia andrei (Oligochaeta). Environ Sci Technol 37:3399-3404 (2003).

$40 \mathrm{Xu} \mathrm{P}$, Liu DH, Diao JL, Lu DH and Zhou ZQ, Enantioselective acute toxicity and bioaccumulation of benalaxyl in earthworm (Eisenia fedtia). J Agric Food Chem 57:8545-8549 (2009). 